\title{
Editorials
}

\section{Epigenetics and primary care}

Epigenetics is the study of how changes to chromosome structure record and/ or transmit changes in the expression of genes. Epigenetic mechanisms act during development to control mechanisms such as cell proliferation and differentiation, tissue formation, organogenesis, and the emergence of physiological function. They also act throughout life to regulate gene expression over the long term. Epigenetic mechanisms respond to a wide range of biological signals, including stimuli from the external and social environments. So, why should this matter to general practice?

We know that poverty and socioeconomic deprivation are directly linked to premature mortality and morbidity. 'We also know that, despite universal access to free health care, inequitable healthcare outcomes persist in socioeconomically deprived populations. ${ }^{2}$ Although some of the disease-causing effects of poverty and deprivation are biologically direct, such as inadequate diet or exposure to alcohol, tobacco, and other toxins, there may also be later-emerging effects, in which epigenetic mechanisms play a part.

\section{EPIGENETICS ACROSS THE LIFECOURSE}

Although scientific understanding of the mechanisms by which adversity and social inequality lead to health consequences is still developing, it seems likely that processes are involved that regulate the production of inflammatory cytokines and stress hormones such as noradrenaline and cortisol. Together the accumulated effect of these stress-related biological signals is known as allostatic load. ${ }^{3}$ It refers to allostasis, the process of restoring physiological set-points after exposure to stressors (which may be environmental or social). Repeated or chronic exposure to stressors appears to erode the capacity of allostatic mechanisms to restore physiological set-points, and so promote survival under duress. Thus, over time, the consequences of prolonged exposure to stressors become more pronounced. By helping us to understand how these processes change, epigenetics provides an explanatory model through which the biological embedding of low socioeconomic status (SES) affects the functioning of a person's genome. In turn this model has begun to stimulate new ways of thinking about how environmental factors such as

epigenetics provides an explanatory model through which the biological embedding of low socioeconomic status (SES) affects the functioning of a person's

\section{genome.}

social inequality generate or perpetuate health inequalities.

Evidence of long-lasting epigenetic effects has been clearly observed in the consequences of the Dutch Winter Famine during 1944-1945. For several months, the daily rations in Amsterdam were between 400 and 800 calories. The survivors were a well-defined group of individuals, all of whom suffered just this single period of malnutrition, at exactly the same time. Epidemiologists followed up not just the adult survivors but also the offspring of women who were pregnant during the famine. Early gestation-exposed individuals showed a three-fold increase in coronary heart disease, a more atherogenic lipid profile, increased levels of obesity, increased risk of type 2 diabetes, and an increased risk of breast cancer..$^{4-6}$ Other studies of famine have shown similar results, ${ }^{5}$ and these effects are now being seen in the grandchildren of the women who were malnourished during the first 3 months of their pregnancy. ${ }^{4.7}$ Starvation is not the only trigger for long-lasting impacts: other population studies have demonstrated associations between maternal mental wellbeing, child abuse, and low SES with regard to poor long-term mental health and chronic disease. ${ }^{8,9}$ Furthermore, it seems likely that the increase in type 2 diabetes worldwide - while to some extent heritable - is developing too quickly to be due to genetic differences, but appears to be more long-lasting than the direct exposures to adversity. ${ }^{10}$

\section{HOW DO ENVIRONMENTAL EXPOSURES BECOME BIOLOGICALLY EMBEDDED,}

\section{AND CAN THEY BE REVERSED?}

Epigenetic mechanisms influence the structure of chromatin, which is the complex formed of DNA and chromosomal histone proteins. Chromatin structure influences the accessibility of DNA to the gene transcription machinery, which drives differentiation of every cell type, all of which have the same DNA, by regulating the expression of different genes. A cell, organ, or person's phenotype is thus determined not only by genome but also by the epigenome. At present, there are three well-understood mechanisms by which epigenetic factors affect gene expression: DNA methylation, histone modification, and non-coding RNA-mediated pathways. DNA methylation usually results in gene silencing or reduced gene expression. A wide range of histone modifications are known that either increase or decrease the amount of gene transcription, depending on the modification. Finally, microRNAs (miRNAs) are a class of non-coding singlestranded RNAs of 19-25 nucleotides in length, which regulate gene expression by binding to complementary sequences within messenger RNAs (mRNAs), blocking mRNA translation and/or promoting mRNA degradation.

Although there is abundant information about how these epigenetic mechanisms are deployed extensively in somatic tissues, their roles in the transgenerational transmission of chronic disease risks, via the germ line, are less well understood. One likely explanation of how epigenetic changes may be passed from one generation to another is that, during pregnancy, the foetal germ cells that will give rise to the these effects are now being seen in the grandchildren of the women who were malnourished during the first 3 months of their pregnancy. 


\section{many of our patients from socioeconomically deprived backgrounds are disadvantaged not only by the immediate lack of access to material, nutritional, and educational support that are conducive to the development and expression of capabilities for flourishing, but also by the cumulative biological embedding of their ongoing social deprivation ...}

mother's grandchildren are exposed to the same environmental factors as both the mother and the somatic tissues of the fetus. Epigenetic modifications could thus be acquired by fetal germ cells during gestation, the functional impacts of which may not emerge until later life."

As epigenetic mechanisms are regulators of gene expression, it is important to ask whether, once applied, they are reversible. This appears to be the case: for instance, there is accumulating evidence that mindbody therapies designed to reduce stressrelated arousal and promote coping are associated with reductions in expression of genes for proinflammatory cytokines. ${ }^{12}$

\section{WHAT ARE THE IMPLICATIONS OF EPIGENETICS FOR PRIMARY CARE?}

The GP core curriculum emphasises the need to understand the physical health of our patients in combination with the psychological, socioeconomic, and cultural dimensions of health. If the epigenome is modifying gene expression, as a direct but sustained or delayed - response to environmental stressors, then the need to move from the primacy of a biomedical model to an integrative holistic approach becomes particularly important. An epigenetic explanatory model allows us to see how many of our patients from socioeconomically deprived backgrounds are disadvantaged not only by the immediate lack of access to material, nutritional, and educational support that are conducive to the development and expression of capabilities for flourishing, but also by the cumulative biological embedding of their ongoing social deprivation, which perpetuates and indeed further widens health and societal inequity. ${ }^{13}$ In the case of symptoms such as chronic widespread pain, ${ }^{14}$ where epidemiology shows strong associations with social adversity, but immediate causal links between stress and symptoms are rare, ${ }^{15}$ epigenetic mechanisms provide potentially useful material for GPs to construct 'rational' explanations ${ }^{16}$ about the complex links between adversity and illness. Recent progress in epigenetics research raises many questions about how the social and environmental determinants of health influence disease risk, and there is a growing awareness of the potential ethical, social, and legal implications of these findings. ${ }^{17}$ Future progress in this field will benefit from the development of collaborative communities of laboratory, behavioural, and social scientists, clinicians, and policymakers, working with patients and the wider public, in the conduct of pioneering research that will help to improve health outcomes for all.

\section{REFERENCES}

1. Tudor Hart J. The inverse care law. Lancet 1971; 297(7696): 405-412. http://linkinghub. elsevier.com/retrieve/pii/S014067367192410X laccessed 24 Nov 2017).

2. Watt G. What can the NHS do to prevent and reduce health inequalities? Br J Gen Pract 2013; DOI: https://doi.org/10.3399/bjgp13X671803.

3. McEwen B, Stella E. Stress and the individual mechanisms leading to disease. Arch Intern Med 1993; 153(18): 2093-2101.

4. Painter RC, Osmond C, Gluckman P, et al. Transgenerational effects of prenatal exposure to the Dutch famine on neonatal adiposity and health in later life. BJOG 2008, 115(10): 1243-1249

5. van Abeelen AFM, Elias SG, Bossuyt PMM et al. Famine exposure in the young and the risk of type 2 diabetes in adulthood. Diabetes. 2012; 61(9): 2255-2260.

6. Painter RC, De Rooij SR, Bossuyt PMM, et al. A possible link between prenatal exposure to famine report and breast cancer a preliminary study. Am J Hum Biol 2006; 18(6): 853-856.

7. Veenendaal MVE, Painter RC, De Rooij SR et al. Transgenerational effects of prenatal exposure to the 1944-45 Dutch famine. BJOG 2013; 120(5): 548-553.

8. Horwitz AV, Widom CS, McLaughlin J, White HR. The impact of childhood abuse and neglect on adult mental health: a prospective study. J Health Soc Behav 2001; 42(6): 184-201.

9. Leenen FAD, Muller CP, Turner JD. DNA

\section{ADDRESS FOR CORRESPONDENCE}

\section{David B Lehane}

Academic Unit of Primary Medical Care, Samuel Fox House, Northern General Hospital, Herries Road, Sheffield, S5 7AU, UK

\section{E-mail: d.lehanedasheffield.ac.uk}

\section{David B Lehane,}

NIHR Clinical Lecture and GP, Academic Unit of Primary Medical Care, Northern General Hospital, Sheffield.

\section{Vincent T Cunliffe,}

Senior Lecturer in Developmental Genetics, Department of Biomedical Science, University of Sheffield, Sheffield

\section{Caroline Mitchell}

Senior Clinical Lecturer and GP, Academic Unit of Primary Medical Care, Northern General Hospital, Sheffield

\section{Chris Burton}

Professor of Primary Medical Care and GP. Academic Unit of Primary Medical Care, Northern General Hospital, Sheffield.

\section{Provenance}

Commissioned; not externally peer reviewed.

DOI: https://doi.org/10.3399/bjgp17X693977

methylation: conducting the orchestra from exposure to phenotype? Clin Epigenetics 2016; 8(1): 92.

10. Ling C, Groop L. Epigenetics: a molecular link between environmental factors and type 2 diabetes. Diabetes 2009; 58(12): 2718-2725.

11. Bohacek J, Mansuy IM. Molecular insights into transgenerational non-genetic inheritance of acquired behaviours. Nat Rev Genet 2015; 16(11): 641-652.

12. Bower J, Irwin M. Mind-body therapies and control of inflammatory biology: a descriptive review. Brain Behav Immun 2016; 51: 1-11.

13. Cunliffe VT. The epigenetic impacts of social stress: how does social adversity become biologically embedded? Epigenomics 2016; 8(12): 1653-1669

14. Livshits G, Malkin I, Freidin MB , et at. Genome-wide methylation analysis of large population sample shows neurological pathways involvement in chronic widespread musculoskeletal pain. Pain 2017; 158(6): 1053-1062.

15. Van Gils A, Burton C, Bos EH, et al. Individual variation in temporal relationships between stress and functional somatic symptoms. $J$ Psychosom Res 2014; 77(1): 34-39

16. Burton C, Lucassen P, Aamland A, Olde Hartman T. Explaining symptoms after negative tests: towards a rational explanation $J R$ Soc Med 2015; 108(3): 84-88.

17. Rothstein MA, Cai Y, Marchant GE. The ghost in our genes: legal and ethical implications of epigenetics. Health Matrix Clevel 2009; 19(1): $1-62$. 